\title{
Balancing the Medicine Wheel Through Physical Activity
}

\author{
Lynn F. Lavallée
}

Ryerson University

digital.library.ryerson.ca/object/86

Please Cite:

Lavallée, L. F. (2008). Balancing the medicine wheel through physical activity. Journal of Aboriginal Health, 4(1), 64-71.

$\underline{\text { doi: } 10.18357 / \mathrm{ijih} 41200812316}$

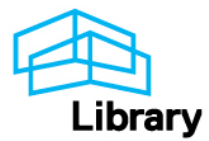




\title{
Balancing the Medicine Wheel through Physical Activity
}

\author{
Lynn Lavallée, PhD, Assistant Professor, School of Social Work, Ryerson University
}

\begin{abstract}
This article highlights the findings of a research project based on the medicine wheel teachings of balance between the physical, mental, spiritual, and emotional aspects of oneself. Specifically, this traditional approach to understanding health was used to explore the impacts of physical activity on emotional, spiritual and mental well-being. Four female participants in a martial arts program at an urban Friendship Centre told their stories at two sharing circles. Afterwards, they were given six weeks to develop symbols that represented the meaning of the martial arts program to them and how it had impacted their lives. The participants named this second method "Anishnaabe Symbol-Based Reflection." This article provides a brief overview of these Indigenous methods and explains how they were applied to this research project. The article then focuses on two key themes that emerged from the Aboriginal women's stories: issues related to identity and to a sense of not deserving good things in life. The women described how they were able to work through some of their identity issues and their low sense of self-worth through their participation in the martial arts program.
\end{abstract}

\section{KEYWORDS}

Urban Aboriginal women, health, medicine wheel, identity, self-esteem, physical activity, martial arts

\section{INTRODUCTION}

$\mathrm{T}$ The research project profiled in this article set out to explore the impacts of physical activity on the well-being of Aboriginal women. The health benefits of participating in physical activities — such as controlling diabetes and other chronic diseases, as well as decreasing the risk of developing cardiovascular disease, high blood pressure, colon cancer, and obesity - are well researched (U.S. Department of Health and Human Services, 1996; Warbuton, Nicol \& Bredin, 2006). However, the psychological, social and cultural benefits of physical activity are less understood (Halas, 2001; Morris, Sallybanks, Willis \& Makkai, 2003). This project therefore focused on how people felt that physical activity impacted them emotionally, socially and culturally.

The theoretical framework used to guide this project was the Indigenous teaching of the medicine wheel. This teaching, as it relates to an individual's health, is based on maintaining balance between four realms: mental, spiritual, emotional, and physical. (National Aboriginal Health Organization, 2005). Healing from trauma and grief includes re-establishing the balance between these four realms (Anishnawbe Health Clinic, 2006).

These medicine wheel teachings guided the development of the following research questions: 1) Did the participants feel that their involvement in a physical activity program impacted their emotional, mental and spiritual well-being? 2) If yes, how did they perceive that impact? And how did they explain the connection between the physical activity and their emotional, mental and spiritual well-being?

The physical activity explored in this research project was martial arts. A martial arts program has been offered 
through the Native Canadian Centre of Toronto (NCCT) since 1999. This program is not just a physical recreation activity, it is also a social, cultural and spiritual program. The instructor, George Lepine, is Cree and brings his Aboriginal teachings into the classroom. Two types of martial arts are taught: tae kwon do and Oki Chi Taw. Lepine founded Oki Chi Taw, which is an Indigenous martial art and warrior system focused on using the weaponry of the Plains Cree- the tomahawk, gun stock war club, short lance, and long knife. Oki Chi Taw is recognized by the World Martial Arts Union as the official Indigenous martial art of Canada (Native Canadian Centre, 2006).

The research described in this article was part of a larger study that involved 17 people-10 men and seven women (Lavallée, 2007). Four of the seven women were Aboriginal, ranging in age from 32 to 42 . These women were primarily of Ojibwe, Cree and Métis heritage and their stories are the ones highlighted in this article. The women's real names are not used; rather they are referred to using pseudonyms that they chose for themselves. These pseudonyms were: Hawk, White Spider, Turtle and Bimadiziwin. This article focuses on the experiences of the four Aboriginal women to allow for a more detailed description and analysis of their stories. Two themes in particular-identity and "undeservingness" - are discussed. Both themes were unique to the Aboriginal women who participated in the project.

\section{METHODOLOGY}

\section{Sharing circles}

The participants' experiences with the martial arts program were described during two sharing circles. The use of sharing circles in Indigenous research has been described as "circle methodology," a method that can be familiar and comforting for Indigenous research participants because the circle has a long tradition in Indigenous cultures (Restoule, 2006). Sharing circles are similar to focus groups, however the former incorporate culturally appropriate protocols. All of the participants were familiar with Ojibwe teachings and protocols, so the customs of smudging and presenting tobacco bundles to participants were incorporated into the sharing circle process. Tobacco is a sacred plant that was given as a gift to the participants as recognition of their willingness to share their knowledge and to ensure that the sharing circle was done in a respectful way. Smudging can be done by burning sage, sweet grass or other medicines. The smoke from these medicines is used to smudge a room, people or objects (V. Harper, personal communication, April 2002).
There were two sharing circles held to accommodate the participants' schedules. The discussions in the sharing circles were guided by the medicine wheel teachings. The discussions focused on documenting participants' stories about their decision to participate in the martial arts program, as well as what impact, if any, the program had had on their lives. The participants were asked how their involvement in the program had impacted their lives physically, emotionally, spiritually, and mentally.

\section{Anishnaabe Symbol-Based Reflection}

Symbols, the making of symbols and art that displays symbols have significant cultural and spiritual meanings among many Aboriginal people. When an Aboriginal artist makes something - a painting, jewellery, a medicine wheel, or a dream catcher - their energy is said to be placed into that object. The making of symbols and art is often a very spiritual and unique experience for each individual (K. Wheatley, personal communication, August 2004). Symbols are often considered sacred because of this spiritual significance. For these reasons, using symbols in research is an ideal approach that reflects an Indigenous method.

The name of this research method, Anishnaabe SymbolBased Reflection, was developed with the participants. The term Anishnaabe is used primarily by Aboriginal people who identify as Ojibwe, Algonquin, Oji-Cree and Odawa (Eigenbrod, Kakegamic \& Fiddler, 2003). At the end of each sharing circle, participants were asked if they wanted to participate in the Anishnaabe Symbol-Based Reflection. All four Aboriginal women participated in this second method. The women were asked to think about a symbol that captured the meaning of the martial arts program in their lives. They were told that they could either make the symbol themselves or purchase it. Participants were given approximately 6 weeks to make or purchase their symbols. A maximum of $\$ 30$ was provided to each participant to cover the cost of the materials.

\section{RESULTS}

\section{Stories about identity}

The Aboriginal women told stories about their identity and how their involvement in the program caused them to reflect on their identity, particularly in regards to how their identity related to their urban environment. Their stories spoke of the importance of having the martial arts program offered through an Aboriginal cultural centre and taught by an Aboriginal instructor. They were prompted to reflect 
on their identity as a direct result of their participation in the physical activity program because the instructor incorporated Indigenous teachings. From time to time, all four women participated in other cultural programs at the NCCT, such as women's drumming and singing. Hawk described how she felt she fit in at the NCCT and within the martial arts program.

\section{Hawk's Story}

I'm Métis. My identity can be concealed, but inside I'm not white. I was born up North and got darker in the summer and people treated you differently. But, in Toronto, everyone is different. No one can tell what you are. But I grew up in lower income areas. I never saw the connection, even though I had Native friends. But they were First Nations and I was Métis, so there was a difference. But once I walked through the doors of the Native Canadian Centre, I saw people who looked like me. It's one place I come and I fit in. I didn't know that would happen when coming here. I looked in people's eyes and my identity became a lot more clear as a result of me participating in the tae kwon do program and different cultural programs here at the Native Canadian Centre. (personal communication, October, 2005)

\section{Symbols representing family identity in the urban environment}

White Spider's symbol (Figure 1) consisted of photographs on each side of a large sheet. On one side was her Cree family, which included herself as a child, her brother, mother, Nanan (grandmother), and Mushoom (grandfather). Turning over the picture exposed a more recent photograph

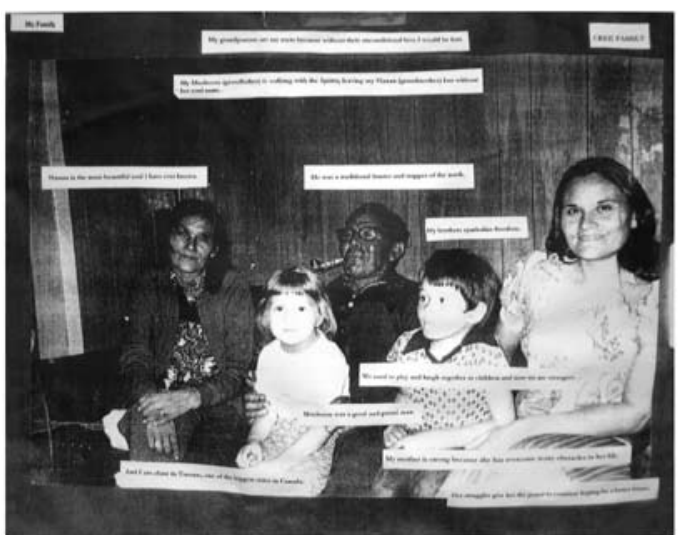

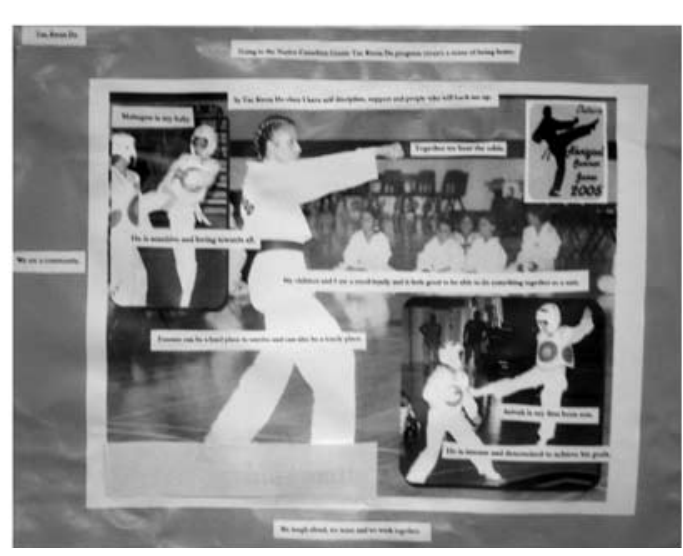

Figure 1. White Spider's Cree Family of her and her sons competing at the Ontario Aboriginal Sport Circle Games in 2005. Within each picture she placed captions that described the pictures. She described her Cree family:

My grandparents are my roots because without their unconditional love I would be lost. My Mushoom is walking with the Spirits, leaving my Nanan lost without her soul mate. Nanan is the most beautiful soul I have ever known. He [Mushoom] was a traditional hunter and trapper of the north. Mushoom was a good and proud man. My brother symbolizes freedom, we used to play and laugh together as children and now we are strangers. My mother is strong because she has overcome many obstacles in her life. Her struggles give her the power to continue hoping for a better future... . And I am alone in Toronto, one of the biggest cities in Canada. (personal communication, February, 2006)

White Spider called the reverse side of the sheet "Tae kwon do - we are a community" and wrote the following to describe these pictures:

Toronto can be a hard place to survive and can also be a lonely place. Going to the Native Canadian Centre tae kwon do program creates a sense of being home. We laugh out loud, we tease and work together. In tae kwon do class, I have self-discipline, support and people who will back me up. My children and I are a small family and it feels good to be able to do something together as a unit. (personal communication, October, 2005)

White Spider described her sons with affection: "Baby Spider is my baby. He is sensitive and loving towards all. Big Spider is my first-born son. He is intense and determined to achieve his goals. Together we can beat the odds!" (personal communication, October, 2005).

Kirmayer, Brass and Tait (2000) stated that the attempted forced assimilation and resulting cultural genocide of Indigenous people has left many 
people with "profound problems of identity and self-esteem" (p. 6). White Spider spoke of her family's identity being impacted by moving to the big city, while Hawk spoke about her identity becoming clearer after participating in the program. Their stories correlated with the issues of identity noted by Kirmayer, Brass and Tait.

\section{"Undeservingness," self-worth and self-esteem}

The following stories relate to the second theme: issues of self-esteem. Participants used the term "undeservingness" to describe a sense of poor self-worth and low self-esteem. Turtle and White Spider described these issues as stemming from their pasts. Turtle said that she had an abusive family background and that, because of that, she came to believe that it was "okay" to accept physical violence in her personal relationships.

\section{Turtle's Story:}

I grew up in an abusive family and I did not admit or recognize that it was abuse until I was an adult. I didn't know that it was wrong. I didn't have a lot of friends. I didn't go to a lot of people's homes. I thought I grew up in a very loving environment. And then, on the weekends, all hell would break loose, you know: the parties and the drinking and the violence. I am very accepting of physical violence. It is okay with me; very okay. And coming to this class, I realize that there's good physical violence and there's bad. I didn't draw the line between the two in my personal relationships, and it was all okay, and I realize it is not okay. I grew up in a very dysfunctional, violent, typical, rez type of family, even though I grew up in the city. (personal communication, October, 2005)

Turtle later described how the martial arts program made her realize that she needed to work on her self-esteem:

Tae kwon do has showed me that I have to work on my self-esteem. I have raised my self-esteem in the time that I've been here. I still need to work on it. If I felt like I was deserving, my self-esteem would be in a different place. I'm a black belt now, and I don't feel this huge sense of accomplishment, like I'm so wonderful. If you ask me about it, I want to shrink away and, kind of, you know, I want to hide. I don't want to advertise it. I don't say, "Yes, I am a black belt and I'm wonderful," because I don't feel like that. (personal communication, October, 2005)
Turtle's history of family violence had a direct impact on her self-esteem, causing her to develop and tolerate unhealthy personal relationships. The martial arts program awakened her self-esteem and yet, in spite of all her progress in this area, she recognizes that she has more work to do build up her sense of self-worth.

White Spider spoke about how Turtle's story is a familiar one and that feelings of "undeservingness" are common throughout the Aboriginal community.

\section{White Spider's Story:}

There's a lot of stuff that goes on in our community, [including] abuse. Anyway, [somebody] said something to me, and I had to kind of set him straight. He said, "Your boys don't realize what they have. They don't know. You took them to China, you did this, and you did that." And I was like, "And your point is what? Just because they are Native kids, they have to suffer? Is that what you are trying to tell me? That just because we've had such a rough start, what, now my kids, because they are Indian, they have to have a hard life? Why? Tell me why!" (personal communication, October, 2005)

White Spider spoke of the pride she felt from participating in martial arts. She felt that Aboriginal people do not always feel a sense of pride even when they should. She recalled a situation where Hawk expressed feelings of "undeservingness."

I remember talking to Hawk-I hope you don't mind me sharing this. You were talking about your car and you said, "I don't know if I want to be driving around a [nice car]." I was looking at you saying, "So, just because you're Indian you don't have to be driving around a rez car!"We deserve good things in our lives. You know, it's something you earned. It's okay! (personal communication, October, 2005)

\section{Symbols representing healing}

Although the women shared stories related to issues of identity and self-esteem, they also shared stories of strength and healing. Three of the women used the symbols of the medicine wheel and the medicine shield to represent the healing they experienced related to their involvement in the program. Along with their symbols, they wrote a story explaining the meaning of their symbol. Their stories are reproduced verbatim and in full. 
Turtle's symbol (Figure 2) was an amalgam of the medicine shield, dream catcher and medicine wheel symbols. Turtle wrote this story explaining her symbol:

This piece of artwork was created and designed specifically to provide a symbolic reflection or representation of what tae kwon do means to me. I titled my project Threads of Connection because it seems the most appropriate way to express my experience here and the importance of the program to me. The format was completely natural to me because it was a direct expression of my identity and the interconnectedness of tae kwon do in my life.

I chose three rings for a multitude of reasons. Some I will explain and some will have to wait for perhaps another time. Circles have no beginning and no end, and that's how I have come to view my experience here. It has no real beginning and no end. I will always be a part of this program in some way. The three rings represent the mind, body and spirit principles of martial arts. Each ring is wrapped in black to signify the concept of the Great Unknown that we all hear Master Lepine refer to. It is also currently where I stand as a black belt in the program.

The 1st ring: This is a medicine shield and I chose this to represent me. On it I have placed my clan colors which are green and brown, because I am turtle clan. The background represents the place of new beginnings or birth. It is the place where I started the program, as a white belt. The silver centre is a representation of the energy that we are all born with. It denotes a vibrational energy that emits quickness and eagerness. I remember how I felt when I first began tae kwon do. I wanted everything in a hurry—quick, quick, quick! I was eager for knowledge and skill. As I have matured in the program, I have mellowed into a golden energy that has the vibrational energy of refinement and patience, so I put silver and gold beads around my clan colours.

The 2nd ring: This is a dream catcher and I chose this to represent how we are taught to let the bad experiences go and hang on to all the good ones. Inside the dream catcher I have placed the various belt colours on various levels, from black outside to white and yellow in the middle. I did it this way deliberately, to demonstrate the levels of learning and how they expand as you progress and develop. In the beginning my knowledge was limited, but as I grew though each belt level my knowledge grew as well. The interconnectedness of knowledge and experience is perfectly demonstrated through the webbing of the dream catcher. As a beginning student in this program, I could not have grown without the help of everyone in the program to some degree. Each person contributed to my personal growth in a very profound and interconnected manner.

The 3rd ring: This is a medicine wheel, which is a profound teaching tool in Aboriginal culture. It seemed very appropriate to choose this symbol because of its symbolic significance. It takes a lifetime of learning to scratch the surface of the knowledge and teachings encoded in this traditional learning tool. I see my involvement with tae kwon do in the same manner. It will take a lifetime of learning just to scratch the surface of the knowledge encoded in martial arts as a whole. I chose to make this ring the smallest ring to represent the idea that big things come in small packages. Getting involved in the program initially seemed like a small thing to do. But, in retrospect, it was a huge step that has resulted in never ending gifts of knowledge, healing, self-preservation, respect, commitment and opportunity that I have never experienced in any other activity I have tried.

Our club is located in a home-because it is a home for me in so many ways - filled with a family that I value far more than I take the opportunity to acknowledge very much. (personal communication, October, 2005)

Bimadiziwin's medicine wheel keychain (Figure 3) symbolized her "life journey to strive for balance" (personal communication, February, 2006). This is her story explaining why she chose the medicine wheel to represent her involvement in the martial arts program:

I wrote this to express how I have found the Seven Grandfather Teachings in the do jang [martial arts 
gym], which assists me in my life journey to strive for balance and to make my medicine wheel more complete. The Seven Grandfathers are: Honesty, Humility, Respect, Courage, Kindness, Love, and Truth. These teachings were left to us to show us how we should live. I have given my personal experiences and thoughts for how I have experienced these teaching in the do jang.

Humility: The day I walked through the doors and bowed to the flags, the Master instructor and the fellow members, I was very humbled because it was a place unknown where I had to learn to follow proper etiquette and tae kwon do techniques. I also had to deal with the fact that I was physically awkward and was probably looking very silly trying to figure things out.

Courage: Being involved with tae kwon do has further enhanced my abilities and given me more courage to continually challenge myself in all aspects of my life so that I may continue to strive for growth and change.

Honesty: In tae kwon do, it can be a very emotional experience. Many inner challenges arise that have forced me to look honestly within myself.

Truth: My truth is practicing tae kwon do, which helps me in living a good life.

Respect: Respect has always been a main teaching in my life. In a world where there seems to be a loss of the value for respect, the do jang is a place that reinforces honest and decent conduct.

Love: I feel there is an aura of love in our do jang: a love for the freedom of physical movement, for the sense of community, for the friendships, and for the members, who unselfishly share their kindness with one another.

Kindness: There is much kindness in the do jang. It is a place that is supportive, non-judgmental and accepting. Tae kwon do members willingly give their gifts of support, respect, knowledge, and encouragement to all.

In closing, I would like to share that I never thought I would find so much peace in a place that I originally thought was all about the art of fighting. I would like to take this opportunity to express my heartfelt gratitude to all the members who unselfishly give of themselves for the benefit of others! Chi Miigwetch! As for my symbol, I have created a medicine wheel keychain to remind me of my ultimate goal in how I need to live my life and how tae kwon do and the Seven Grandfathers lay a path for me to get there.

Nahow. (personal

communication,

February, 2006)

Hawk combined two symbols together for her work (Figure 4)—one, a medicine wheel with a hawk in the centre; the other, a song, which she sung during the sharing circle with the help of one of the other members. The hawk represented her identity and the song represented the strength she got from the program. As with many traditional Aboriginal songs, the song that Hawk chose (Strong Women's Song) did not contain lyrics but was rather composed of vocal melodies.

The symbols that depict the meaning of the martial arts program, and everything I've experienced because of it, are my medicine wheel and the Strong Women's Song. For me, martial arts was the door that led me further into my healing journey. It led me through the Native Canadian Centre doors-my umbilical cord to Mother Earth. It lead me to meet people for the first time in my adult life who were like me, people who I can just look at and it's as if they know what is in my heart and can speak to my spirit. I don't have to explain myself. I know that not all Native people are searching for their identity, but my life has been a life-long journey of trying to understand who and what I am. This has caused problems for me. I understand now that the biggest problem was the sense of undeservingness I have. I don't think of it as a lack of self-esteem. Coming here is opening my eyes that I am deserving. I am deserving of my black belt. I am deserving of having people care about me and not hurt me. My medicine wheel with the hawk - my clan—symbolizes my healing journey and the growing understanding I have of myself as an Anishnaabe.

My undeservingness as a woman: I'm understanding through our informal healing circles in the bathroom, and the strength that I get when I walk through these doors, that my undeservingness is a 


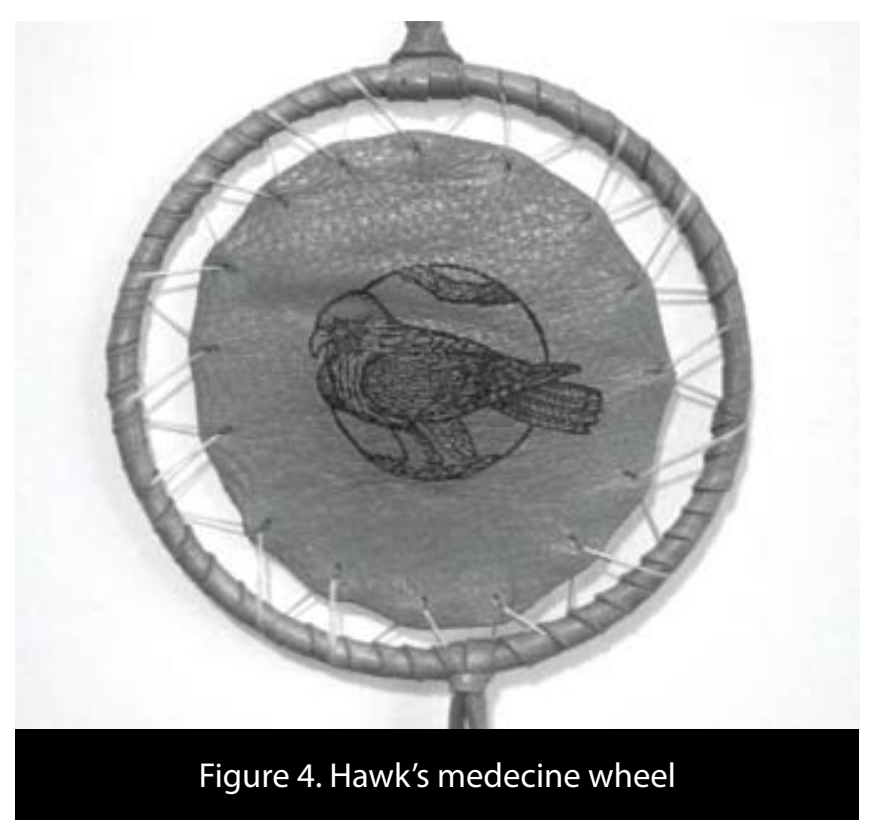

symptom that comes from our long history and how we unlearned our ways to respect women. It comes from my Dad, and his Dad, and so on. And, in turn, the men I have selected act similarly because I'm comfortable with and expect to be treated unwell. So my next symbol is the Strong Women's Song-the song that I know has brought me helpers to unlearn this lack of deserving. (personal communication, February, 2006)

The healing journey described by each woman was different, however the two main themes related to this healing were identity and "undeservingness." Hawk spoke about "undeservingness" and Turtle used the term selfesteem. For both women, this was described as part of their healing journey. Hawk directly related her feelings of "undeservingness" to issues with her identity as an Aboriginal woman. White Spider passionately spoke about the sense of "undeservingness" in the Aboriginal community and how we need to change this way of thinking. Bimadiziwin spoke about balance being important to her well-being and how the teachings of the Seven Grandfathers was an important part of this balance.

\section{DISCUSSION}

The women's stories spoke about their Aboriginal identity, particularly how their identity relates to living in the urban environment. They spoke about their identity being lost in the city. Reclaiming their urban Aboriginal identity through their involvement in the martial arts program and other cultural programs at the NCCT was a significant factor for these women. Their stories suggest the importance of creating ways for Aboriginal people, particularly urban Aboriginal people, to reclaim their identities. The martial arts program incorporated Indigenous teachings and the women also attended other programs at the NCCT. For at least one participant, the martial arts program served as a catalyst for her healing journey and for learning more about her culture.

Social identity is a person's knowledge of belonging to a social category or group (Stets \& Burke, 2000). The martial arts program, and other programs that the women participated in at the Native Canadian Centre, fostered in the women a sense of belonging and a sense of community. For the four Aboriginal women, this program formed a large part of their social identity. They identified with the urban Aboriginal community and with each other. The program filled a void in the women's sense of identity and provided them with a sense of belonging to a social group.

This research demonstrates the importance of Aboriginal cultural centres that offer a multitude of programs, including physical activity programs. It is recommended that health programs be offered in a culturally welcoming way and that they be offered alongside other cultural programs through an Aboriginal cultural centre so that participants can experience other cultural events and socialize with other Aboriginal people.

Feelings of "undeservingness" and the participant's sense of identity were discussed throughout the women's stories. Hawk spoke about how "undeservingness" was a symptom of colonization and how this was passed on through the generations. Turtle spoke about being accepting of physical violence because this is what she had confronted throughout her life. Anderson's (2000) theories about the construction of a negative female Native identity and the self-fulfilling prophecy may help to elaborate on why these women expect to be treated unjustly. According to Anderson, the media and society have crafted a stereotypical image of Native women as easy, lazy, drunken and/or dirty squaws. This damaging portrayal of female Native identity has an impact on female Natives' beliefs about themselves. Anderson argues that we need to get rid of these negative images and replace them with more accurate and constructive ones. Through the participant's reclamation of identity and self-esteem, these women are attempting to discard these negative stereotypical images - both the stereotypes that society has of Aboriginal women and the stereotypes that the Aboriginal women have of themselves. 


\section{CONCLUSION}

This project set out to explore the impact of physical activity on the wellness of Aboriginal women. The rationale for this research was embedded in the teachings of the medicine wheel, which embraces a holistic understanding of health based on the balance of physical, emotional, mental, and spiritual well-being. The women told stories about identity, "undeservingness" and self-esteem. Through their involvement in the martial arts program, the women were able to begin their healing journey.

Future programs for Aboriginal people should recognize the way in which participants work through the impacts of colonization, including aspects of identity and self-worth. It is important to recognize how Aboriginal people experience these impacts in their daily lives. The "undeservingness" and lack of self-esteem that many of the Aboriginal women felt were linked closely to issues of identity. The martial arts program, organized in a culturally positive environment, proved to be an avenue in which these women could work towards healing these issues.

\section{ACKNOWLEDGEMENTS}

Chi Meegwetch to the women who shared their stories and to the instructor of the program, George Lepine for supporting this project. Ah Hi to Elder Vern Harper for his guidance. Meegwetch to Lee Maracle for her support in editing parts of my thesis that impacted the writing of this article. Thank you to the Wellesley Institute for providing funds for this project.

\section{REFERENCES}

Anderson, K. (2000). A recognition of being: Reconstructing Native womanhood. Toronto, ON: Sumach Press.

Anishnawbe Health Clinic (2006). Anishnawbe health brochure. Toronto, ON: Anishnawbe Health Clinic.

Eigenbrod, R., Kakegamic, G., \& Fiddler, J. (2003). Aboriginal literatures in Canada: A teacher's resource guide. Ottawa, ON: Curriculum Services Canada.

Halas, J. (2001). Playtime at the treatment centre: How physical activity helps troubled youth. Avante, 7(1), 1-13.
Kirmayer, L., Brass, G., \& Tait, C. (2000). The mental health of Aboriginal peoples: Transformations of identity and community. Canadian Journal of Psychiatry, 45, 607-616.

Lavallée, L. (2007). Threads of connection: Healing the undeservingness of Indigenous people through cultural recreational programming. Doctoral Dissertation, University of Toronto.

Morris, L., Sallybanks, J., Willis, K., \& Makkai, T. (2003). Sport, physical activity and antisocial behaviour in youth. Trends and issues in crime and criminal justice. Australian Institute of Criminology. Retrieved May 3, 2007, from http://www.aic. gov.au

National Aboriginal Health Organization. (2005). First Nations regional longitudinal health survey (RHS) 2002/03: The peoples' report. Ottawa: Author.

Native Canadian Centre (2006). Native Canadian centre martial arts. Retrieved July 20, 2006, from http://www.ncct.on.ca/ martialartsprogram.html

Restoule, J. P. (2006). Male Aboriginal identity formation in urban areas: A focus on process and context. Doctoral dissertation. University of Toronto.

Stets, J., \& Burke, P. (2000). Identity theory and social identity theory. Social Psychology Quarterly, 63(3), 224-237.

U.S. Department of Health and Human Services (1996). Physical activity and health: A report of the Surgeon General. Atlanta, GA: U.S. Department of Health and Human Services, Centre for Disease Control and Prevention, National Centre for Chronic Disease Prevention and Health Promotion.

Warbuton, D. E. R., Nicol, C. W., \& Bredin, S. S. D. (2006). Health benefits of physical activity: The evidence. Canadian Medical Association Journal, 174(6), 801-809.

\section{END NOTES}

1. The Seven Grandfathers outlined are based on the participant's teaching. It is recognized that some teachings include truth in place of kindness. Kindness is one of the Thirteen Grandparents. The Thirteen Grandparents incorporates the female aspect (L. Maracle, personal communication, January 2007). 